obviate the need to send blood samples to the laboratory.

We thank Dr L Stimmler for permission to study his patients and Boehringer Corporation (London) Limited for supplying BM-test-glycemie and Reflotest strips.

\section{References}

1 Cornblath M, Segal S, Smith C A. Carbohydrate and energy metabolism in the newborn: an international exploration. Pediatrics 1967 ; 39: 582-602.
2 Anonymous. Hypoglycaemia in infancy and childhood. Br Med J 1971; iii: 130.

3 Worth R, Johnston D G, Anderson J, Alberti K G M M. Letter: Performance of blood-glucose strips. Lancet 1979; ii: 742 .

4 Dacombe C M, Dalton R G, Goldie D J, Osborne J P. Effect of packed cell volume on blood glucose estimations. Arch Dis Child 1981; 56: 789-91.

Correspondence to Dr B H Wilkins, Hillingdon Hospital, Uxbridge, Middlesex UB8 3NN.

Received 15 July 1982

\title{
Effects of fresh frozen plasma infusions on coagulation screening tests in neonates
}

\author{
C A JOHNSON, M S SNYDER, AND R L WEAVER \\ Winston-Salem, North Carolina, USA
}

SUMMARY Infusion of fresh frozen plasma to 23 immature infants with respiratory distress syndrome produced full correction of prothrombin time and activated partial thromboplastin time in only 7 . Improvements in coagulation studies failed to correlate with gestational age or with the initial degree of coagulation abnormality.

There is currently no standard approach to the management of immature or sick neonates with demonstrable coagulation abnormalities, but many authorities recommend that such infants be treated empirically with fresh frozen plasma (FFP) in the hope of preventing excessive damage from potential intracranial or intrapulmonary bleeding. However, there is no clinical evidence that this approach is reliably effective in reversing abnormal coagulation data in the neonate. In this study 23 infants with immaturity and mild to moderate respiratory distress syndrome received FFP in an attempt to support blood pressure. Prothrombin time (PT), activated partial thromboplastin time (PTT), quantitative platelet count, and levels of fibrinogen were determined before and after infusion to determine the effect of plasma on coagulation status in these infants.

\section{Materials and methods}

Babies studied. In our intensive care nursery FFP is sometimes used as a volume expander for attempted control of hypotension. We studied the effects of FFP infusions on the coagulation parameters in infants treated. Altogether 32 infants were studied within the first 48 hours of life. Nine infants were subsequently omitted from the study either because they demonstrated no abnormalities in coagulation studies before FFP infusion or because they hadc evidence of disseminated intravascular coagulation. All of the 23 patients remaining in the study survived.

Gestational ages ranged from 28 to 38 weeks. Birthweights ranged from 965 to $4450 \mathrm{~g}$. One infant was felt to be large for gestational age; none was judged to be small for gestational age. Twenty of the 23 infants had mild to moderate respiratory distress. PT, PTT, platelet count, and fibrinogen levels were determined in all infants before FFP infusion, and again 15 minutes after completion of plasma infusion. All infants received FFP in a volume of $10 \mathrm{ml} / \mathrm{kg}$.

Laboratory methods. Whole blood, in a volume of $1.8 \mathrm{ml}$, was obtained by a 2-syringe technique through a 23-gauge scalp vein needle or through an indwelling umbilical artery catheter. Blood was transferred immediately to a tube containing buffered sodium citrate in a ratio of $9: 1$. Plasma was separated at $4^{\circ} \mathrm{C}$ for 15 minutes at $10000 \mathrm{rev} / \mathrm{min}$. PT and PTT were done as previously described. ${ }^{1}$ The concentration of fibrinogen was determined by microtechnique as described by Searcy et al. ${ }^{2}$ Platelet counts were done by phase microscopy.

\section{Results}

Twenty-three infants with abnormally prolonged PT or PTT were treated with FFP in a dose of $10 \mathrm{ml} / \mathrm{kg}$. 
Table Comparison of infants with coagulation studies correcting and failing to correct after fresh frozen plasma infusion

\begin{tabular}{llll}
\hline & $\begin{array}{l}\text { Infants correcting }(n=7) \\
(\text { mean } \pm S D)\end{array}$ & $\begin{array}{l}\text { Infants failing to correct }(n=16) \\
(\text { mean } \pm S D)\end{array}$ & $\begin{array}{c}\text { Analysis of variance } \\
\text { probability* }\end{array}$ \\
\hline Gestational age & $33 \cdot 0 \pm 2 \cdot 4$ & $32 \cdot 3 \pm 2 \cdot 9$ & $0 \cdot 53$ \\
Prothrombin time & $14 \cdot 5 \pm 1 \cdot 4$ & $15 \cdot 6 \pm 2 \cdot 4$ & $0 \cdot 27$ \\
$\begin{array}{l}\text { Activated partial thromboplastin } \\
\text { time (seconds) }\end{array}$ & $89 \cdot 9 \pm 20 \cdot 0$ & $93 \cdot 1 \pm 19 \cdot 2$ & $0 \cdot 64$ \\
\hline
\end{tabular}

* Significant if $<0.05 . \mathrm{SD}=$ Standard deviation.

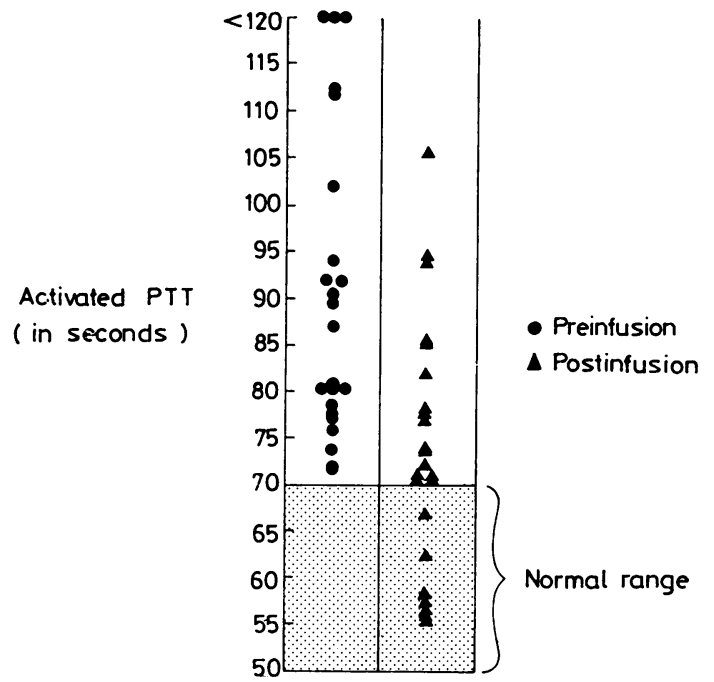

Figure Results of activated partial thromboplastin times $(P T T)$ in infants pre- and post-fresh frozen plasma $(10 \mathrm{ml} / \mathrm{kg}$ ) infusion. 'Normal' range is that expected in term, healthy infants.

No study infant, before FFP, had a platelet count lower than $150 \times 10^{9} / 1$ or a fibrinogen level below $1.5 \mathrm{~g} / 1$. Three infants, before FFP, demonstrated a PT greater than 18 seconds. In all 3 it returned to normal after plasma infusion. All 23 infants had a PTT greater than 70 seconds before FFP infusion. (In our laboratory the normal range for PTT is $30-45$ seconds; 70 seconds is considered at the upper limit of normal for the term newborn.) In 7 of 23 infants, complete correction of PTT was achieved (Figure). However, 16 infants or $70 \%$ of the study group, failed to correct PTT to less than 70 seconds. Correction of clotting parameters failed to correlate with infants' gestational age, or with the apparent severity of initial coagulation deficiency (Table).

\section{Discussion}

The population studied included infants who were preterm (21 of 23) and had mild to moderate respiratory distress syndrome (20 of 23). Any infant with severe respiratory distress, asphyxia, apnoea, suspected disseminated intravascular coagulation, or bacterial sepsis was excluded. Prolonged coagulation screening tests in the study group would be expected to be secondary to deficiencies of the vitamin $K$ dependent coagulation factors or to the contact factors. Both groups of factors are known to be reduced in immature infants and in infants with respiratory distress syndrome. ${ }^{3-5}$ We did not attempt fully to characterise various types and severities of the coagulation disorders nor even to study their clinical significance. We simply attempted to determine whether this very common intensive care nursery population could be easily approached by empirical FFP transfusion, thereby obviating the need for more detailed coagulation studies of individual infants.

Unfortunately such would not appear to be a reasonable approach, as the majority of infants failed to show substantial improvement in clotting parameters. The current study was not sufficiently detailed to explain why certain infants failed to correct in response to FFP. Those failing to correct may have had particularly severe or multiple deficiencies, or they may have had increased extravascular or catabolic loss of infused coagulant proteins.

Our data suggest that, as a group, immature infants and infants with mild to moderate respiratory distress may have coagulation abnormalities that will not respond to empirical FFP transfusion. Such infants, if bleeding, should ideally have detailed coagulation studies before plasma treatment. If standard dose FFP is used for correction of detected deficiencies, coagulation studies should be monitored, since correction is not predictable or consistent. Infants failing to correct may warrant a more aggressive replacement-such as partial plasma exchange.

\section{References}

1 Johnson C A, Abildgaard C F, Schulman I. Absence of coagulation abnormalities in children with cyanotic congenital heart disease. Lancet 1968; ii : 660-2. 
2 Searcy R L, Simms N M, Low M Y. A simple method for rapid detection of hypofibrinogenemia. Am J Med Technol 1967; 33: 326-9.

${ }^{3}$ Chessells $\mathbf{J} \mathbf{M}$, Wigglesworth $\mathbf{J} \mathbf{S}$. Coagulation studies in preterm infants with respiratory distress and intracranial haemorrhage. Arch Dis Child 1970; 47: 564-70.

4 Hathaway W E, Bonnar J. Perinatal coagulation. New York: Grune \& Stratton, 1978: 135-6.
5 Bleyer W A, Hakami N, Shepard T H. The development of hemostasis in the human fetus and newborn infant. J Pediatr 1976; 79: 838-53.

Correspondence to Dr C A Johnson, Department of Pediatrics, Bowman Gray School of Medicine, 300 South Hawthorne Road, Winston-Salem, North Carolina 27103, USA.

Received 21 June 1982

\title{
Caseating regional lymphadenitis complicating BCG vaccination: a report of 6 cases
}

\author{
PAUL K H TAM, A B STROEBEL, H SAING, J T K LAU, AND G B ONG \\ Department of Surgery and Department of Microbiology, University of Hong Kong, \\ Queen Mary Hospital, Hong Kong
}

SUMMARY Six infants had caseating regional lymphadenitis complicating BCG vaccination. There was a delayed onset and a lack of immediate vaccination complications. Three infants had frank abscesses. Additional affected nodes undetected clinically were found at operation in all cases. All lymph nodes contained tubercles, 3 showing acidfast bacilli, 2 of which grew Mycobacterium bovis. Complete excision followed by antituberculous chemotherapy produced satisfactory results.

Although the efficacy of BCG vaccination in protection against tuberculosis is still a subject of much debate, ${ }^{1}$ the procedure has generally been regarded as safe. Complications have been reported as uncommon. ${ }^{2}$ Development of regional lymphadenitis has been described. However these data were concerned mainly with epidemiology. ${ }^{3}$ Detailed information on microbiology, pathology, management and its result were lacking.

We have recently noted an increase in incidence of this form of complication in our hospital-six cases in 6 months (June 1981-November 1981) and would therefore like to report our experience.

\section{Patients}

All 6 infants in this series received BCG vaccination during the first week of life. Vaccination was administered by a special nurse, with the French vaccine, at a dose of $0.005 \mathrm{mg}$, intradermally in the left arm. Each infant presented with an axillary mass on the side of the vaccination, and one had a supraclavicular mass in addition. The onset varied from 3 to 8 months after vaccination, averaging 6 months (Table). Only one infant gave a history of immediate post-vaccination complication consisting of a rash over the vaccination site which had subsided after a week.

On examination, all the infants were well and active. Only one infant had a low grade fever of $37.5^{\circ} \mathrm{C}$. Three infants had frank axillary abscesses which were pointing, while the other 3 infants had solitary axillary masses which were mainly solid but with areas of fluctuation clearly demonstrable.

\section{Management and results}

Excision was performed for all the infants underō general anaesthesia. Clinically solitary lesions were invariably found to be associated with some other enlarged nodes deeper down and all these were removed. Frank abscesses were not incised but rather excised in toto with elliptical incisions. The wounds were sutured in 3 infants and left open in three.

On cutting open, all enlarged nodes showed caseation at centres. Histopathology of the abscess walls and lymph nodes of all 6 infants showed the presence of tubercles with caseous necrosis, epithelioid cells, and Langhans' giant cells.

The caseous material obtained either in the frank abscess or in the centres of enlarged nodes was examined microscopically and cultured for acidfast bacilli. Acid-fast bacilli were demonstrated in only 3 of 6 patients. Only 2 of these were culture positive and in each Mycobacterium bovis was isolated.

Immunological parameters including total lymphocyte counts, T- and B-cell counts, and lymphocyte response to phytohaemagglutinin and serum immunoglobulin levels were examined and found to be normal. IgG antibodies directed against the antigen 6 fraction of Mycobacterium tuberculosis were increased only in the 3 cases in whom frank abscess formation was present. 